\title{
The clinical and prognostic evaluation of GRP94 immunoexpression in Caucasian patients with colorectal adenocarcinoma
}

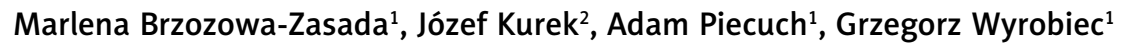 \\ ${ }^{1}$ Department of Histology and Cell Pathology, School of Medicine with the Division of Dentistry in Zabrze, Medical University \\ of Silesia in Katowice, Poland \\ 2Department of General, Endocrinological, and Oncological Surgery, Municipal Hospital, Jaworzno, Poland
}

Gastroenterology Rev 2019; 14 (2): 140-147

DOI: https://doi.org/10.5114/pg.2019.85898

Key words: colorectal adenocarcinoma, GRP94, chaperones, overall survival.

\begin{abstract}
Address for correspondence: Marlena Brzozowa-Zasada PhD, Department of Histology and Cell Pathology, School of Medicine with the Division of Dentistry, Medical University of Silesia, 19 Jordana St, 41-808 Zabrze, Poland, phone: +48 32 2722842,
\end{abstract} e-mail: marlena.brzozowa@op.pl

\begin{abstract}
Introduction: Colorectal cancer (CRC) is traditionally regarded as the most commonly diagnosed gastrointestinal malignant disease. Nevertheless, despite advances in diagnosis and novel therapeutic options, the clinical outcomes of patients are still unsatisfactory.

Aim: To investigate the clinicopathological and prognostic roles of GRP94 expression, the immunohistochemical investigation was performed on samples of CRC tumour tissues, adjacent non-pathological mucosa, and metastatic foci in regional lymph nodes in Caucasian patients.

Material and methods: Paraffin-embedded adenocarcinoma samples were assessed immunohistochemically for GRP94 protein and scored according to the percentage of cells with positive reaction combined with staining intensity. Connections between GRP94 immunoexpression and clinicopathological factors including the overall survival (OS) were evaluated.

Results: The level of the GRP94 immunohistochemical reactivity was correlated with the grade of the histological differentiation $(H(2.92)=25.906 ; p<0.001)$, size of the primary tumour $(Z=-4.010 ; p<0.001)$, regional lymph node involvement $(Z=$ $-6.547 ; p<0.001)$, and perineural invasion $(Z=-6.235 ; p<0.001)$. Kaplan-Meier survival analysis showed that the survival time for patients with a low expression of GRP94 was significantly longer than that for patients with a moderate or strong level of GRP94 immunoreactivity $(p<0.001)$.

Conclusions: An enhanced level of GRP94 immunoexpression was significantly associated with malignancy-related clinicopathological factors and reduced the 5-year overall survival in CRC patients. However, a multivariate analysis demonstrated that GRP94 was not revealed as an independent risk factor for CRC prognosis.
\end{abstract}

\section{Introduction}

Colorectal cancer (CRC) is traditionally regarded as the most commonly diagnosed gastrointestinal malignant disease. Nevertheless, despite advances in diagnosis and novel therapeutic options, the clinical outcomes of CRC patients with locally advanced or metastatic disease are still unsatisfactory. The patients' overall survival (OS) is largely dependent on the disease stage at the time of diagnosis and/or surgical resection [1, 2]. Importantly, approximately $20 \%$ of the diagnoses are made in the metastatic stage of the disease. In this case the percentage of 5-year overall survival is less than
$15 \%$. Importantly, the prognoses are not satisfactory even in the case of patients with primary tumours [3, 4]. Therefore, the identification of novel approaches for describing the patients from the high-risk group, particularly in the context of the clinical outcomes, has become a major challenge $[5,6]$.

Glucose-regulated protein 94 (GRP94) is the endoplasmic reticulum-resident HSP9O stress-inducible chaperone that participates in protein folding [7]. In recent years a large number of proteins whose synthesis and secretion is under the control of GRP94 have been characterised. Among them should be mentioned Toll- 
like receptors, integrins, and the platelet glycoprotein Ib-IX-V complex [8, 9]. Nevertheless, upregulation of GRP94 expression has often been detected in cancers, including breast $[10,11]$, liver [12, 13], lung [14, 15], colorectal $[16,17]$, gastric $[18,19]$, and oesophageal [20-22]. As revealed by studies, the induction of GRP94 expression has been associated with increased cell proliferation, metastasis, drug resistance, and poor clinical outcome of cancer patients.

As mentioned above, expression of GRP94 protein was also upregulated in colorectal cancer. However, it should be noted that the study by Wang et al. was conducted on Chinese patients with CRC (Asians) [16]. Several reports indicate that there are racial disparities in CRC biology and behaviour. Thus, it remains to be determined whether those findings are applicable to the general population with CRC.

\section{Aim}

The current study investigated the expression of GRP94 protein in colorectal adenocarcinoma samples to assess its prognostic significance by correlating its expression with the clinicopathological variables and survival of Caucasian patients.

\section{Material and methods}

\section{Tissue samples}

The study was conducted on formalin-fixed and paraffin-embedded colorectal adenocarcinoma samples archived in the files of the Department of Pathomorphology in Zabrze (Poland). Tissue specimens were received from 92 colorectal adenocarcinoma patients who underwent surgical resection on surgical clinics in 2011. The exclusion criteria were as follows: (1) history of previous malignant disease, (2) familial adenomatous polyposis, (3) inflammatory bowel disease, (4) preoperative anti-cancer treatment, and (5) evidence of distant metastasis. The clinicopathological characteristics obtained from the medical records were as follows: age, gender, location of tumour, grade of tumour differentiation, depth of invasion, tumour size, presence or absence of angio- and perineural invasion, lymph node metastasis, operation record, treatment record, recurrence, and vital status at the last follow-up date.

The specimens belonged to 46 men and 46 women (mean age: 62.5; range: $48.5-71.5$ years). Tumours were located in the proximal part of the colon in 30 (32.60\%) cases, in the distal part of the colon in 31 (33.70\%), and in the rectum in 31 (33.70\%). Three levels of differentiation were used to classify the grading as follows: well differentiated (G1), 35 cases (38.04\%); moderately differentiated (G2), 34 (36.96\%); and poorly differentiated (G3), 23 (25\%) (Table I).
Table I. Demographic, clinical, and tumour-related characteristics of patients included in the study $(n=92)$

\begin{tabular}{|c|c|c|}
\hline Parameter & $N$ & $\%$ \\
\hline \multicolumn{3}{|l|}{ Age: } \\
\hline$\leq 62$ years & 46 & 50.00 \\
\hline$\geq 63$ years & 46 & 50.00 \\
\hline Mean \pm SD & \multicolumn{2}{|c|}{$60.53 \pm 13.79$} \\
\hline Median (Q1-Q3) & \multicolumn{2}{|c|}{$62.5(48.5-71.5)$} \\
\hline Min.-max. & \multicolumn{2}{|c|}{$34-87$} \\
\hline \multicolumn{3}{|l|}{ Gender: } \\
\hline Females & 46 & 50.00 \\
\hline Males & 46 & 50.00 \\
\hline \multicolumn{3}{|l|}{ Location of tumour: } \\
\hline Proximal colon & 30 & 32.60 \\
\hline Distal colon & 31 & 33.70 \\
\hline Rectum & 31 & 33.70 \\
\hline \multicolumn{3}{|c|}{ Grade of histological differentiation: } \\
\hline G1 & 35 & 38.04 \\
\hline G2 & 34 & 36.96 \\
\hline G3 & 23 & 25.00 \\
\hline
\end{tabular}

Depth of invasion:

\begin{tabular}{lll}
\hline T1/T2 & 49 & 53.26 \\
\hline T3/T4 & 43 & 46.74 \\
\hline
\end{tabular}

Size of primary tumour:

\begin{tabular}{lll}
\hline$\leq 9 \mathrm{~cm}$ & 46 & 50.00 \\
\hline$\geq 10 \mathrm{~cm}$ & 46 & 50.00
\end{tabular}

Mean \pm SD $\quad 9.48 \pm 3.64$

Me (Q1-Q3) 9.5 (6-12)

Min.-max. $3-17$

\begin{tabular}{lll}
\hline Angioinvasion: & & \\
\hline No & 43 & 46.74 \\
\hline Yes & 49 & 53.26 \\
\hline
\end{tabular}

\begin{tabular}{lcc}
\hline Regional LN involvement: & & \\
\hline No & 43 & 46.74 \\
\hline Yes & 49 & 53.26 \\
\hline
\end{tabular}

Perineural invasion:

\begin{tabular}{lll}
\hline No & 49 & 53.26 \\
\hline Yes & 43 & 46.74
\end{tabular}




\section{Immunohistochemical staining}

For the immunohistochemical studies the paraffin-embedded specimens were cut into $4-\mu \mathrm{m}$-thick sections, fixed on Polysine slides, deparaffinised in xylene, and rehydrated through a graded series of alcohol. To retrieve the antigenicity, the tissue sections were treated twice with microwaves in a $10 \mathrm{mM}$ citrate buffer $(\mathrm{pH}$ 6.0) for 8 min each. Subsequently, sections were incubated with rabbit polyclonal antibody to GRP94 (final dilution 1 : 1000) (GeneTex; cat. number GTX103232). For visualisation of protein expression, the sections were treated with a BrightVision detection system and Permanent AP Red Kit (Zytomed). Mayer's haematoxylin was used to counterstain the nuclei.

\section{Semi-quantitative analysis of GRP94 expression in colorectal adenocarcinoma samples}

The scores were assigned separately for the stained area and for the intensity of the immunohistochemical reaction. Quantification connected to the stained area of the tissue section was performed as follows: (1) $<33 \%$ of cells showed immunoreaction, (2) 33-66\% of the cells had positive reaction to GRP94, and (3) > 66\% of the cells were positive. The intensity of the immunohistochemical reaction was quantified as follows: (1) absent or weak, (2) moderate, and (3) strong. Each tissue section was characterised by a final grade derived from the multiplication of the stained area and the intensity of the staining. The GRP94 expression was considered to be: absent/low for grade 1; moderate for grades 2, 3, and 4; and strong for grades 6 and 9 .

\section{Survival analysis}

Survival analysis was conducted in 92 patients. The survival curves were generated using the Kaplan-Meier method. The overall survival (OS) was defined as the length of time between surgery and death. The follow-up period was 60 months. Patients alive were censored at 5 years.

\section{Statistical analysis}

Statistical analyses were conducted using Statistica 9.1 (StatSoft, Poland). The clinical characteristics of the patients in relation to GRP94 immunoreactivity were assessed by performing the Kruskal-Wallis test and U Mann-Whitney test. Additionally, using Spearman's rank correlation coefficient the relationship between the immunoexpression of GRP94 and age, grade of tumour differentiation, and size of primary tumour was assessed. The Kaplan-Meier method was used to study survival curves, and the long-rank test to compute differences between the curves.

\section{Results}

To investigate the clinicopathological and prognostic roles of GRP94 expression, the immunohistochemical analysis was performed in CRC tumour tissues, adjacent non- pathological mucosa, and metastatic foci in lymph nodes (Figure 1). It should be noted that only trace expression of this protein was revealed in adjacent non-tumour colorectal mucosa, whereas the high expression was demonstrated in well-, moderately-, and poorly-differentiated tumours (Figures 1, 2). Among the 92 samples, 33 (35.87\%) showed a strong immunohistochemical reaction, 21 (22.83\%) demonstrated moderate immunoreactivity, 29 (31.52\%) revealed weak expression, and 9 (9.78\%) were characterised as negative in the context of GRP94 immunoexpression. Moreover, moderate and strong expression was demonstrated in metastatic foci in lymph nodes.

The relationships between the GRP94 levels and each clinicopathological parameter are summarised in Table II. As demonstrated, the level of the GRP94 immunohistochemical reactivity was correlated with the grade of the histological differentiation $(\mathrm{H}$ (2.92) $=25.906 ; p<0.001)$. A strong expression of GRP94 protein was detected more frequently in patients with G3 tumours $(R=0.521 ; p<0.001)$. A significant correlation was also observed between the strong immunoreactivity of the GRP94 protein and larger tumour size $(Z=-4.010 ; p<0.001)$. The expression of this protein increased with an increase in the tumour size $(R=0.415 ; p<0.001)$. The other clinicopathological variables associated with the immunoexpression of GRP94 included regional lymph node metastasis and perineural invasion. The patients with regional lymph node involvement were characterised by strong GRP94 immunoreactivity $(Z=-6.547 ; p<0.001)$. In samples of patients with perineural invasion, the expression of GRP94 protein was also revealed to be strong $(Z=$ -6.235; $p<0.001$; Table II). The statistical evaluation of GRP94 immunoexpression according to age, sex, tumour location, depth of invasion, and angioinvasion revealed no significant difference among these variables (all $p>0.05$; Table II)

The Kaplan-Meier survival analysis showed that the overall survival rate in the group of patients with a low expression level of GRP94 was significantly longer than that for patients with a moderate or strong level of GRP94 immunoreactivity ( $p<0.001$; Figure 3 ). The 5 -year overall survival for patients with a low, moderate, or strong level of GRP94 immunoexpression was $68.4 \%, 14.3 \%$, and $12.1 \%$, respectively. The GRP94-low patients had an average survival time of 56.474 months (95\% Cl: 54.401-58.547), whereas the GRP-moderate expression and GRP94-strong expression groups had an 

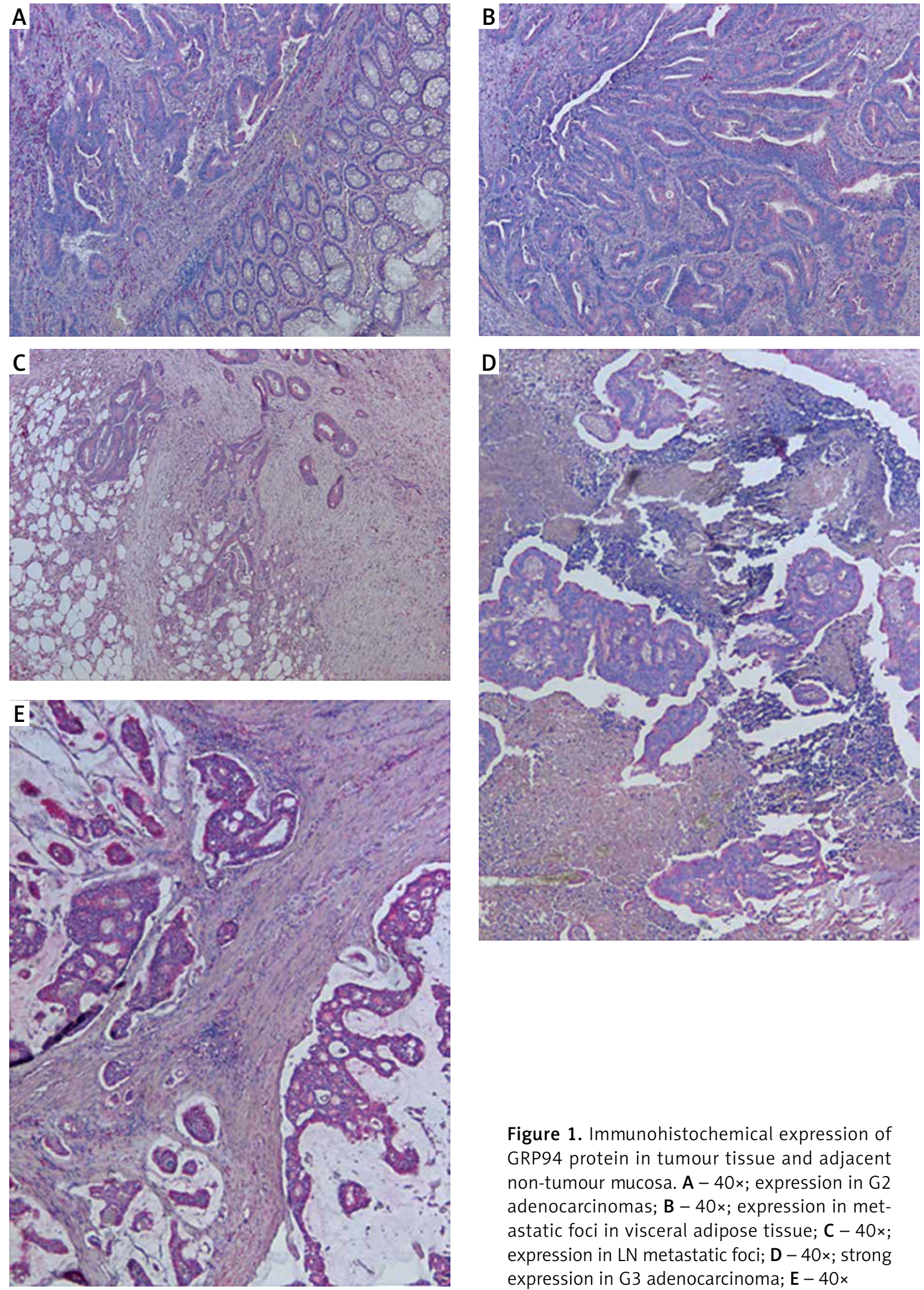

Figure 1. Immunohistochemical expression of GRP94 protein in tumour tissue and adjacent non-tumour mucosa. A - 40x; expression in $\mathrm{G} 2$ adenocarcinomas; $\mathbf{B}-40 x$; expression in metastatic foci in visceral adipose tissue; C - 40x; expression in LN metastatic foci; D - 40x; strong expression in $\mathrm{G} 3$ adenocarcinoma; $\mathrm{E}-40$ x 


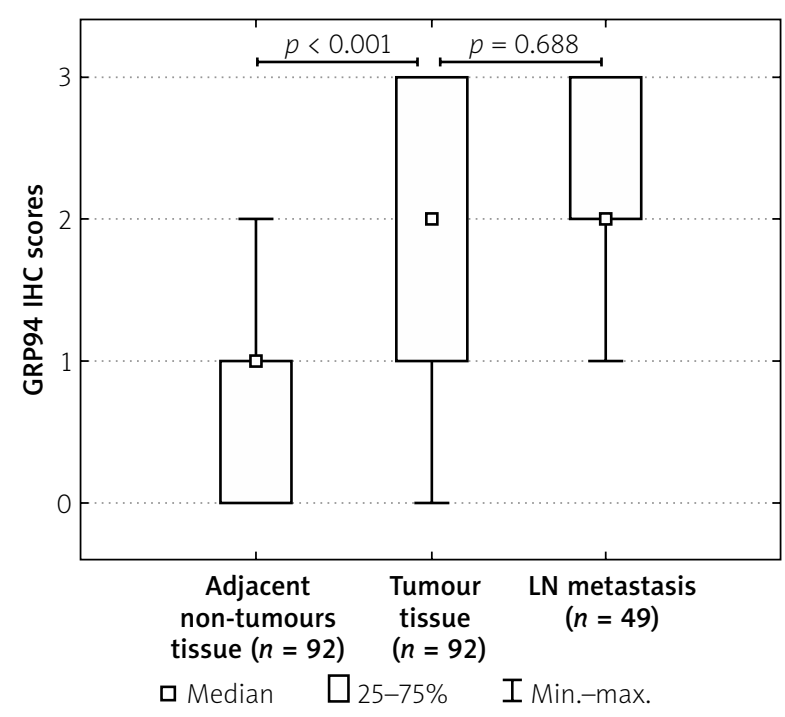

Figure 2. Immunoexpression of GRP94 in CRC tumour tissues, adjacent non-tumour tissues, and metastatic foci in lymph nodes

average survival time of 31.47 (95\% Cl: 23.12-39.82) and 22.42 months (95\% Cl: $16.86-27.98)$, respectively. The average survival time for all of the patients was 38.55 months (95\% Cl: 34.28-42.82; Table III).

In the univariate analysis the age, grade of tumour differentiation, depth of tumour invasion, size of primary tumour, angioinvasion, regional lymph node involvement, perineural invasion, and GRP94 immuno-

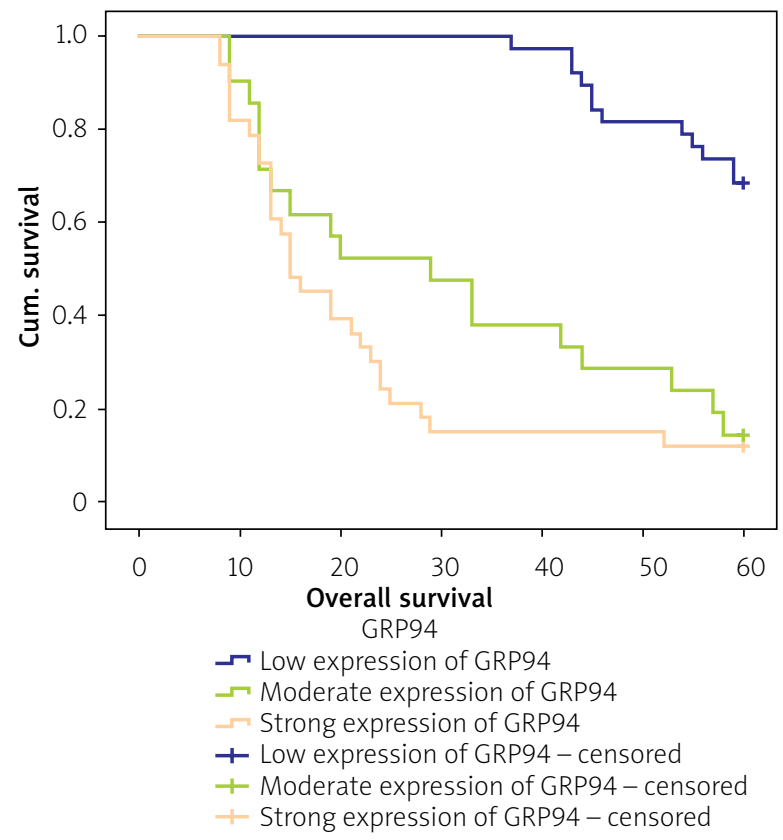

Figure 3. Kaplan-Meier survival curves of CRC patients with different expression of GRP94 protein; follow-up period $=60$ months expression were found to be significantly associated with reduced 5-year survival. Nevertheless, a multivariate analysis demonstrated that only age $(\mathrm{HR}=1.875$; $95 \% \mathrm{Cl}: 1.063-3.307, p=0.030)$, grade of tumour differentiation $(\mathrm{HR}=17.133 ; 95 \% \mathrm{Cl}: 6.673-43.990$, $p<0.001)$, angioinvasion ( $\mathrm{HR}=0.208$; $95 \% \mathrm{Cl}$ : $0.077-$ $0.559, p=0.002$ ), and regional lymph node involvement $(\mathrm{HR}=2.745 ; 95 \% \mathrm{Cl}: 1.006-7.491, p=0.049)$ were the independent risk factors for worse survival (Table IV).

\section{Discussion}

In the current study a high expression of GRP94 protein was observed in primary colorectal adenocarcinoma foci and metastatic foci in LNs. Moreover, the high level of GRP94 immunoexpression in tumour tissues was demonstrated to be strongly correlated with malignancy-related clinicopathological factors and 5-year overall survival of Caucasian patients. It should be pointed out that the high expression of GRP94 was significantly associated with advanced histological tumour grade. The Kruskal-Wallis test showed a statistical difference between the patients with $\mathrm{G} 1$ tumours and those with $\mathrm{G} 2$ tumours, and between the patients with G1 tumours and those with G3 tumours. In both cases, patients with G1 tumours were characterised by a low level of GRP94 expression $(R=0.521 ; p<0.001)$. U Mann-Whitney test and Spearman's rank correlation coefficient demonstrated that strong GRP94 expression was related to increased tumour size and the presence of perineural invasion, suggesting that this protein might participate in the malignant formation and tumour progression. For example, in breast carcinomas, the expression of GRP94 has been thought to be a marker of brain metastasis [23]. It should be mentioned that similar results have been obtained by Wang et al. in Chinese patients with CRC. Moreover, in cases of breast, gastric, and prostate carcinomas, GRP94 overexpression has also been associated with an advanced stage of the disease [10, $11,18,24]$. The high expression of GRP94 in metastatic foci in lymph nodes may indicate that colorectal cancer cells with such expression are characterised by enhanced capacity for metastasis formation. It should also be mentioned that an enhanced level of GRP94 immunoexpression was significantly associated with worse overall survival in CRC patients. Similar results have been obtained in patients with oesophageal adenocarcinomas [21]. Nevertheless, a multivariate analysis demonstrated that GRP94 was not revealed as an independent risk factor for CRC prognosis. Similar results were reported by Takahashi et al. in Japanese patients with CRC [17] and Zheng et al. in gastric cancer patients [18]. 
Table II. Correlations between GRP94 immunoexpression and clinicopathological characteristics in CRC patients

\begin{tabular}{|c|c|c|c|c|c|}
\hline \multirow[t]{2}{*}{ Parameter } & & \multicolumn{3}{|c|}{ The immunoexpression level of GRP94 } & \multirow[t]{2}{*}{ Statistical analysis } \\
\hline & & Low & Moderate & Strong & \\
\hline \multirow[t]{4}{*}{ Age } & \multirow[t]{2}{*}{$\leq 62$ years } & 21 & 8 & 17 & \multirow{4}{*}{$\begin{array}{c}Z=-0.373, p=0.710 \\
R=0.044, p=0.677\end{array}$} \\
\hline & & $45.65 \%$ & $17.39 \%$ & $36.96 \%$ & \\
\hline & \multirow[t]{2}{*}{$>63$ years } & 17 & 13 & 16 & \\
\hline & & $36.96 \%$ & $28.26 \%$ & $34.78 \%$ & \\
\hline \multirow[t]{4}{*}{ Gender } & \multirow[t]{2}{*}{ Females } & 17 & 12 & 17 & \multirow[t]{4}{*}{$Z=0.905, p=0.366$} \\
\hline & & $36.96 \%$ & $26.09 \%$ & $36.96 \%$ & \\
\hline & \multirow[t]{2}{*}{ Males } & 21 & 9 & 16 & \\
\hline & & $45.65 \%$ & $19.57 \%$ & $34.78 \%$ & \\
\hline \multirow[t]{6}{*}{ Location of tumour } & \multirow[t]{2}{*}{ Proximal colon } & 12 & 7 & 11 & \multirow{6}{*}{$\begin{array}{c}H(2.92)=0.269 \\
p=0.874\end{array}$} \\
\hline & & $40.00 \%$ & $23.33 \%$ & $36.67 \%$ & \\
\hline & \multirow[t]{2}{*}{ Distal colon } & 12 & 10 & 9 & \\
\hline & & $38.71 \%$ & $32.26 \%$ & $29.03 \%$ & \\
\hline & \multirow[t]{2}{*}{ Rectum } & 14 & 4 & 13 & \\
\hline & & $45.16 \%$ & $12.90 \%$ & $41.94 \%$ & \\
\hline \multirow{6}{*}{$\begin{array}{l}\text { Grade of histological } \\
\text { differentiation }\end{array}$} & \multirow[t]{2}{*}{ G1 } & 24 & 6 & 5 & \multirow{6}{*}{$\begin{array}{c}H(2.92)=25.906 \\
p<0.001 \\
1-2,1-3 \\
R=0.521, p<0.001\end{array}$} \\
\hline & & $68.57 \%$ & $17.14 \%$ & $14.29 \%$ & \\
\hline & \multirow[t]{2}{*}{ G2 } & 14 & 8 & 12 & \\
\hline & & $41.18 \%$ & $23.53 \%$ & $35.29 \%$ & \\
\hline & \multirow[t]{2}{*}{ G3 } & 0 & 7 & 16 & \\
\hline & & $0.00 \%$ & $30.43 \%$ & $69.57 \%$ & \\
\hline \multirow[t]{4}{*}{ Depth of invasion } & \multirow[t]{2}{*}{$\mathrm{T} 1 / \mathrm{T} 2$} & 23 & 11 & 15 & \multirow[t]{4}{*}{$Z=-1.477, p=0.159$} \\
\hline & & $46.94 \%$ & $22.45 \%$ & $30.61 \%$ & \\
\hline & \multirow[t]{2}{*}{$\mathrm{T} 3 / \mathrm{T} 4$} & 15 & 10 & 18 & \\
\hline & & $34.88 \%$ & $23.26 \%$ & $41.86 \%$ & \\
\hline Size of primary & $\leq 9 \mathrm{~cm}$ & 30 & 8 & 8 & $Z=-4.010, p<0.001$ \\
\hline & & $65.22 \%$ & $17.39 \%$ & $17.39 \%$ & $R=0.415, p<0.001$ \\
\hline & $>10 \mathrm{~cm}$ & 8 & 13 & 25 & \\
\hline & & $17.39 \%$ & $28.26 \%$ & $54.35 \%$ & \\
\hline Angioinvasion & No & 20 & 11 & 12 & $Z=-1.337, p=0.181$ \\
\hline & & $46.51 \%$ & $25.58 \%$ & $27.91 \%$ & \\
\hline & Yes & 18 & 10 & 21 & \\
\hline & & $36.73 \%$ & $20.41 \%$ & $42.86 \%$ & \\
\hline Regional LN & No & 32 & 10 & 1 & $Z=-6.547, p<0.001$ \\
\hline involvement & & $74.42 \%$ & $23.26 \%$ & $2.33 \%$ & \\
\hline & Yes & 6 & 11 & 32 & \\
\hline & & $12.24 \%$ & $22.45 \%$ & $65.31 \%$ & \\
\hline Perineural invasion & No & 34 & 12 & 3 & $Z=-6.235, p<0.001$ \\
\hline & & $69.39 \%$ & $24.49 \%$ & $6.12 \%$ & \\
\hline & Yes & 4 & 9 & 30 & \\
\hline & & $9.30 \%$ & $20.93 \%$ & $69.77 \%$ & \\
\hline
\end{tabular}

H - The Kruskal-Wallis test, Z-U Mann-Whitney test, $R$-Spearman's rank correlation coefficient. 
Table III. Means and medians for survival time of CRC patients according to GRP94 immunoexpression

\begin{tabular}{|c|c|c|c|c|c|c|c|c|}
\hline \multirow[t]{3}{*}{ GRP94 } & \multicolumn{4}{|c|}{ Mean } & \multicolumn{4}{|c|}{ Median } \\
\hline & \multirow[t]{2}{*}{ Estimate } & \multirow[t]{2}{*}{ Std. error } & \multicolumn{2}{|c|}{$95 \%$ confidence interval } & \multirow[t]{2}{*}{ Estimate } & \multirow[t]{2}{*}{ Std. error } & \multicolumn{2}{|c|}{$95 \%$ confidence interval } \\
\hline & & & Lower bound & Upper bound & & & Lower bound & Upper bound \\
\hline Grade $0-1$ & 56.474 & 1.058 & 54.401 & 58.547 & - & - & - & - \\
\hline Grade 2 & 31.476 & 4.261 & 23.125 & 39.827 & 29.000 & 8.010 & 13.300 & 44.700 \\
\hline Grade 3 & 22.424 & 2.835 & 16.868 & 27.981 & 15.000 & 2.392 & 10.311 & 19.689 \\
\hline Overall & 38.554 & 2.180 & 34.282 & 42.827 & 44.000 & 9.110 & 26.145 & 61.855 \\
\hline
\end{tabular}

Table IV. Multivariate analyses of various prognostic parameters in CRC patients using Cox regression analyses

\begin{tabular}{lccc} 
Prognostic parameter & HR & $\mathbf{9 5 \% ~ C l}$ & $P$-value \\
\hline Age $(>62$ vs. $\leq 62)$ & 1.875 & $1.063-3.307$ & 0.030 \\
\hline Gender (male vs. female) & - & - & - \\
\hline Grade & 17.133 & $6.673-43.990$ & $<0.001$ \\
\hline Depth of invasion & 0.793 & $0.403-1.560$ & 0.502 \\
\hline Size of primary tumour (> 9 vs. $\leq 9)$ & 1.967 & $0.847-4.568$ & 0.116 \\
\hline Angioinvasion (yes vs. no) & 0.208 & $0.077-0.559$ & 0.002 \\
\hline Regional LN involvement (yes vs. no) & 2.745 & $1.006-7.491$ & 0.049 \\
\hline Perineural invasion (yes vs. no) & 0.982 & $0.428-2.250$ & 0.965
\end{tabular}

GRP94 as a pro-oncogenic chaperone might be directly or indirectly involved in cancer development. The pharmacological or genetic inhibition of GRP94 attenuated the proliferation and expansion of HCC cells [12]. GRP94 knockdown suppressed HCC cell metastasis by inhibiting CCT8/c-Jun/EMT signalling [13]. In contrast, Huang et al. revealed that GRP94 silencing blocked AKT signalling and inhibited liver tumour growth in a mouse xenograft model, suggesting that GRP94/AKT signalling could be regarded as an attractive target for cancer therapy [25]. Patel et al. revealed that in the $\mathrm{SkBr} 3$ breast cancer cell line with HER2 expression, the pharmacological inactivation of GRP94 destabilised HER2 and inhibited RAF1-MAPK survival signalling [26]. Moreover, the silencing of GRP94 inhibited the proliferation and migration of highly invasive MDA-MB-231 breast cancer cells [10]. In contrast, the upregulation of GRP94 expression conferred the chemoresistance to etoposide (VP-16) in the lung cancer cell line SK-MES-1 [27] and Adriamycin in ovarian carcinoma cells [28]. The high expression of this chaperone is also one of the mechanisms associated with an increased resistance to radiation therapy [29]. As molecular chaperones with protective properties, GRP94 may protect cells against apoptotic cell death. For example, Hua et al. have demonstrated that GRP94 deficiency in human multiple myeloma cells resulted in apoptosis through the inhibition of the Wnt-survivin pathway [30]. Sim- ilar results have been obtained in human gastric cells SGC-7901 after transfection by psiSTRIKE/Grp94 [31].

\section{Conclusions}

The results of our study revealed a correlation between strong GRP94 immunoexpression and advanced histological tumour grade. Moreover, the high level of GRP94 immunoexpression was correlated with increased tumour size, the presence of perineural invasion, and reduced 5-year overall survival. A multivariate analysis revealed that the independent risk factors for CRC prognosis were age, grade of tumour differentiation, angioinvasion, and regional lymph node involvement. Interestingly, GRP94 was not revealed as an independent risk factor for CRC prognosis.

\section{Acknowledgments}

This study was supported by grant KNW-1-105/ $\mathrm{K} / 6 / \mathrm{I}$ of the Medical University of Silesia.

\section{Conflict of interest}

The authors declare no conflict of interest.

\section{References}

1. Muller MF, Ibrahim AE, Arends MJ. Molecular pathological classification of colorectal cancer. Virchovs Arch 2016; 469: 125-34. 
2. Ahmad S, Johnson K, Ahmed O, Iqbal N. Advances in the management of colorectal cancer: from biology to treatment. Int J Colorectal Dis 2014; 29: 1031-42.

3. Mody K, Bekaii-Saab T. Clinical Trials and progress in metastatic colon cancer. Surg Oncol Clin N Am 2018; 27: 349-65.

4. Alwers $E$, Jia $M$, Kloor $M$, et al. Associations between molecular classifications of colorectal cancer and patient survival: a systematic review. Clin Gastroenterol Hepatol 2018; S1542-3565: 31536-7.

5. Grizzle WE, Manne U, Weiss HL, et al. Molecular staging of colorectal cancer in African-American and Caucasian patients using phenotypic expression of p53, Bcl-2, MUC-1 and p27(kip1). Int J Cancer 2002; 97: 403-9.

6. Minoo P, Zlobec I, Peterson M, et al. Characterization of rectal, proximal and distal colon cancers based on clinicopathological molecular and protein profiles. Int J Oncol 2010; 37: 707-18.

7. Marzec M, Eletto D, Argon Y. GRP94: An HSP 90-like protein specialized for protein folding and quality control in the endoplasmic reticulum. Biochim Biophys Acta 2012; 1823: 774-87.

8. Staron M, Wu S, Hong F, et al. Heat-shock protein gp96/grp94 is an essential chaperone for the platelet glycoprotein Ib-IX-V complex. Blood 2011; 117: 7136-44.

9. Ansa Addo EA, Thaxton J, Hong F, et al. Clients and oncogenic roles of molecular chaperone gp96/grp94. Curr Top Med Chem 2016; 16: 2765-78.

10. Dejeans N, Glorieux C, Guenin S, et al. Overexpression of GRP94 in breast cancer cells resistant to oxidative stress promotes high levels of cancer cells proliferation and migration: implications for tumor recurrence. Free Radic Biol Med 2012; 52: 993-1002

11. Li X, Sun L, Hou J, et al. Cell membrane gp96 faciliates HER2 dimerization and serves as a novel target in breast cancer. Int J Cancer 2015; 137: 512-24.

12. Rachidi S, Sun S, Wu BX, et al. Endoplasmic reticulum heat shock protein gp96 maintains liver homeostasis and promotes hepatocellular carcinogenesis. J Hepatol 2015; 62: 879-88.

13. Wei PL, Huang CY, Tai CJ, et al. Glucose-regulated protein 94 mediates metastasis by CCT8 and the JNK pathway in hepatocellular carcinoma. Tumour Biol 2016; 37: 8219-27.

14. Wang Q, He Z, Zhang J, et al. Overexpression of endoplasmic reticulum molecular chaperone GRP94 and GRP78 in human lung cancer tissue and its significance. Cancer Detect Prev 2005; 29: 544-51.

15. Li JH, Kang KW, Kim JE, et al. Differential expression of heat shock protein 90 isoforms in small cell lung cancer. Int J Clin Exp Pathol 2015; 8: 9487-93.

16. Wang XP, Qiu FR, Liu GZ, Chen RF. Correlation between clinicopathology and expression of heat shock protein 70 and glucose-regulated protein 94 in human colonic adenocarcinoma. World J Gastroenterol 2005; 11: 1056-9.

17. Takahashi H, Wang JP, Zheng HC, et al. Overexpression of GRP78 and GRP94 is involved in colorectal carcinogenesis. Histol Histpathol 2011; 26: 663-71.

18. Zheng HC, Takahashi H, Li XH, et al. Overexpression of GRP78 and GRP94 are markers of aggressive behavior and poor prognosis in gastric carcinomas. Human Pathol 2008; 39: 1042-9.

19. Zhang X, Zhang L, Wang S, et al. Decreased functional expres sion of Grp78 and Grp94 inhibits proliferation and attenuates apoptosis in human gastric cancer cell line in vitro. Oncol Lett 2015; 9: 1181-6.

20. Langer R, Feith M, Siewert JR, et al. Expression and clinical significance of glucose regulated proteins GRP78 (BIP) and GRP94 (GP96) in human adenocarcinomas of the esophagus. BMC Cancer 2008; 8: 70 .

21. Slotta-Huspenina J, Berg D, Bauer K, et al. Evidence of prognostic relevant expression profiles of heta-shock proteins and glucose-regulated proteins in oesophageal adenocarcinomas. PLoS One 2012; 7: e141420.

22. Huang CY, Lee $\mathrm{CH}$, Tu CC, et al. Glucose regulated protein 94 mediates progression and metastasis of esophageal squamous cell carcinoma via mitochondrial function and the NFkB/COX-2/VEGF axis. Oncotarget 2018; 9: 9425-41.

23. Sanz-Pamplona R, Aragues R, Driouch K, et al. Expression of endoplasmic reticulum stress protein is a candidate marker of brain metastasis in both ErbB-2+ and ErbB2- primary breast tumours. Am J Pathol 2011; 179: 564-79.

24. Suriano R, Ghosh SK, Ashok BT, et al. Differences in glycosylation patterns of heat shock protein, gp 96: implications for prostate cancer prevention. Cancer Res 2005; 65: 6466-75.

25. Huang CY, Batzorig U, Cheng WL, et al. Glucose-regulated protein 94 mediates cancer progression via AKT and eNOS in hepatocellular carcinoma. Tumour Biol 2016; 37: 4295-304.

26. Patel PD, Yan P, Seidler PM, et al. Paralog-selective Hsp90 inhibitors define tumour-specific regulation of Her2. Nat Chem Biol 2013; 9: 677-84.

27. Zhang L, Wang S, Wangtao, et al. Upregulation of GRP78 and GRP94 and its function in chemotherapy resistance to VP-16 in human lung cancer cell line SK-MES-1. Cancer Invest 2009; 27: 453-8.

28. Zhang LY, Zhang XC, Wang LD, et al. Increased expression of GRP94 protein is associated with decreased sensitivity to adriamycin in ovarian carcinoma cell lines. Clin Exp Obstet Gynecol 2008; 35: 257-63.

29. Kubota H, Suzuki T, Takahashi S, et al. Increased expression of GRP94 protein is associated with decreased sensitivity to $X$-rays in cervical cancer cell lines. Int J Radial Biol 2005; 81 : 701-9.

30. Hua Y, Gilbertson SW, Kellner J, et al. Molecular chaperone gp96 is a novel therapeutic target of multiple myeloma. Clin Cancer Res 2013; 19: 6242-51.

31. Zhang X, Zhang L, Wang S, et al. Decreased functional expression of Grp78 and Grp94 inhibits proliferation and attenuates apoptosis in a human gastric cancer cell line in vitro. Oncoll Lett 2015; 9: 1181-86.

Received: 9.10.2018

Accepted; 25.11.2018 